\title{
Os diferentes tipos de uso e cobertura da terra e sua influência nos parâmetros de qualidade da água
}

\author{
The different types of land use and its influence on water quality parameters
}

\author{
André Ricardo Furlan ${ }^{1}$, Rodolfo Cristiano Filipini ${ }^{2}$ e Janete Teresinha Reis ${ }^{3}$ \\ 1,2 Graduando em Geografia, Universidade Federal da Fronteira Sul, Erechim, RS, Brasil \\ andrericardo.furlan@gmail.com; rodolfofilipini@hotmail.com \\ ${ }^{3}$ Dra ${ }^{\mathrm{a}}$ Prof ${ }^{a}$. Universidade Federal da Fronteira Sul, Erechim, RS,Brasil \\ reis. janete@gmail.com
}

\begin{abstract}
Resumo
Esta pesquisa procura avaliar como uso e a cobertura da terra influenciam de forma significativa nos parâmetros de qualidade da água. Como objeto de estudo utilizou-se a bacia hidrográfica do Rio Suzana, a partir de dados referente a população $(2000$ - 2010) e uso de técnicas de sensoriamento remoto que foi importante na análise da vegetação (2000 - 2015), assim como a realização de trabalho de campo na coleta de amostras de água e visualização in loco da paisagem em cada ponto e a posterior análise laboratorial. Os resultados demonstram que o uso e a cobertura da terra em uma bacia hidrográfica são de extrema importância por influenciar diretamente sobre os parâmetros da qualidade da água. Para contemplar este quesito, a preservação da mata ciliar é um elemento primordial. Porém, na bacia hidrográfica do Rio Suzana apresenta um déficit quanto a preservação da mata ciliar, e observou-se diferentes tipos de usos e cobertura da terra configurando conflito em vários pontos de coleta de água. Portanto, dois elementos foram considerados importantes neste estudo: a existência da vegetação, os outros tipos de usos do solo e a população (ser humano) como agente transformador.
\end{abstract}

Palavras-chave: Bacia Hidrográfica; Uso da terra; NDVI

\begin{abstract}
This research seeks to assess how use and land cover significantly influence the water quality parameters. As the object of study used the river basin Suzana, from data related to population (2000 - 2010) and the use of remote sensing techniques was important in the analysis of vegetation (2000 - 2015), as well as the realization field work in collecting water samples and display in place of the landscape at each point and the subsequent laboratory analysis. The results demonstrate that the use and land cover in a watershed are extremely important to influence directly on the parameters of water quality. To address this aspect, the preservation of riparian vegetation is a key element. However, the river basin Suzana has a deficit as the preservation of riparian forest, and there was different types of uses and land cover configuring conflict at various points of collecting water. Therefore, two elements were considered important in this study: the existence of vegetation, other types of land uses and population (human) as an agent.
\end{abstract}

Keywords: Watershed; Land use; NDVI 


\section{Introdução}

Este trabalho apresenta uma análise dos tipos de uso e cobertura da terra e de parâmetros de qualidade da água, observados empiricamente e a partir de análise laboratorial. Além destes, realizar-se-á também a análise de alguns elementos físicos importantes no comportamento local da paisagem. A área de estudo localiza-se na porção noroeste do Estado do Rio Grande do Sul, mais precisamente a Bacia Hidrográfica do Rio Suzana. Esta bacia hidrográfica possui suas principais cabeceiras de drenagens no município de Erechim. No decorrer de seu curso, passa pelos municípios de Três Arroios, Gaurama, Severiano de Almeida, Viadutos e Marcelino Ramos, este último faz divisa com o Estado de Santa Catarina. Porém, ressalta-se que estes municípios pertencem à microrregião de Erechim, localizando-se no noroeste do estado do Rio Grande do Sul.

A bacia hidrográfica é considerada e reconhecida como unidade de planejamento. De acordo com Santos (2004, p.40), que a conceitua como um "sistema natural bem delimitado no espaço, composto por um conjunto de terras topograficamente drenadas por um curso d'água e seus afluentes, onde as interações, pelo menos físicas, são integradas e, assim, mais facilmente interpretadas". Desta forma, nesta unidade territorial ocorrem diversos fenômenos que podem ser analisados, tendo em vista que a bacia hidrográfica deve ser considerada como uma unidade espacial, pois "é um limite nítido para ordenação territorial considerando que não há área de terra, por menor que seja que não se integre a uma bacia hidrográfica e, quando o problema central é água, a solução deve estar estreitamente ligada ao seu manejo e manutenção" (SANTOS, 2004, p. 41). Diante do afirmado, a presente unidade de estudo refere-se à bacia hidrográfica do Rio Suzana. A figura 1 abaixo apresenta a localização da área de estudo, integrada a microrregião de Erechim, RS.

Ao investigar sobre o gerenciamento dos recursos hídricos, destaca-se o Art. 32 da Lei 9433 de 8 de janeiro de 1997, pelo qual, cria-se o Sistema Nacional de Gerenciamento de Recursos Hídricos, que apresenta os seguintes objetivos: "I - coordenar a gestão integrada das águas; II - arbitrar administrativamente os conflitos relacionados com os recursos hídricos; III - implementar a Política Nacional de Recursos Hídricos; IV - planejar, regular e controlar o uso, a preservação e a recuperação dos recursos hídricos;" O último ponto do artigo traz à cobrança devida pelos múltiplos usos dos recursos hídricos.

Para o processamento dos dados que envolvem o gerenciamento dos recursos hídricos, as ferramentas oriundas do Sistema de Informações Geográficas (SIGs), são de extrema importância. Pois, auxiliam no processamento e obtenção dos resultados que se caracterizam em produtos cartográficos, além das técnicas de sensoriamento remoto que é indispensável. Neste contexto, Novo $(1995$, p.1) afirma que o "Sensoriamento Remoto é a utilização de sensores para aquisição de informações sobre objetos e fenômenos sem que haja contato direto entre ele". Assim, para obter os resultados do Índice de Vegetação por Densidade Normatizada (NDVI), Silva; Almeida (2015, p.142), colocam que "os índices de vegetação, derivados de imagens satélites são am-
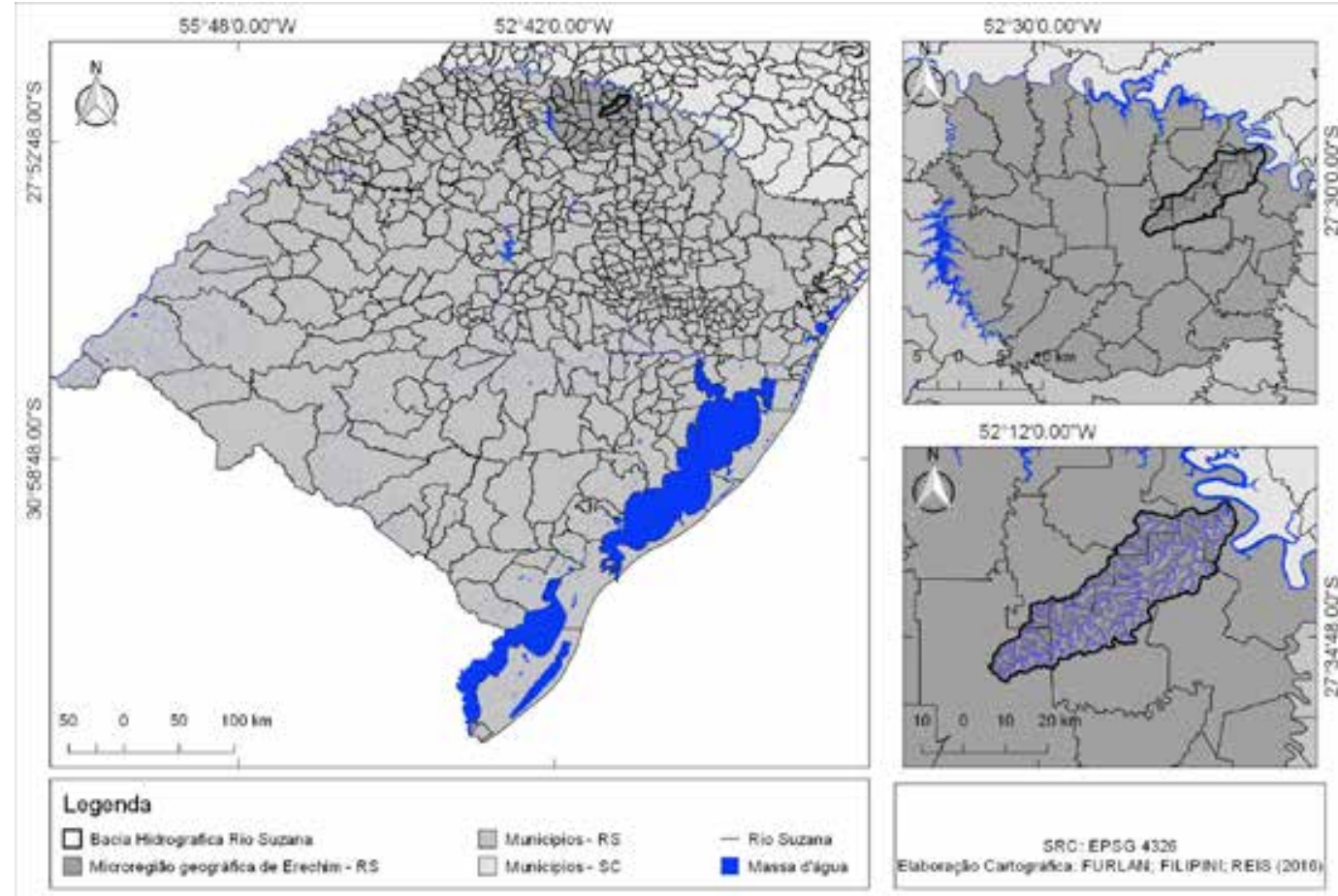

Figura 1 - Localização da área de estudo

Fonte: IBGE (2010) 
plamente utilizados por serem capazes de inferir sobre as modificações nas paisagens, auxiliando no monitoramento da dinâmica da vegetação em áreas degradadas ou em processo de degradação". Portanto, é importante acentuar que a vegetação possui função protetora da camada superficial do solo, evitando a deflagração de processos erosivos e o consequente incremento de sedimentos nos corpos d'água que ocasionam desequilíbrios nos sistemas fluviais. A remoção da vegetação implica em interferência no ciclo e na dinâmica hidrológica localmente, bem como nos processos geomorfológicos e ecológicos, tornando a situação mais grave à medida que estes espaços passam a ser ocupados por construções e pavimentações que aceleram os fluxos de águas superficialmente, com mínimo favorecimento à infiltração das mesmas nos solos (LIMA, 2013).

Para destacar a análise da paisagem realizada na pesquisa, busca-se incorporar as figuras consideradas importantes para o entendimento dos diferentes tipos de uso e cobertura do solo que se encontram no entorno dos pontos de coleta de água que possam interferir nos parâmetros analisados. Assim, registram-se alguns pontos de coleta de dados considerados elementares para a discussão dos elementos que compõe a paisagem. Neste sentido, Bertrand (2004) compreende a paisagem como o " $[. .$. resultado da combinação dinâmica, portanto instável, de elementos físicos, biológicos e antrópicos que, reagindo dialeticamente uns sobre os outros, fazendo da paisagem um conjunto único e indissociável, em perpétua evolução" (BERTRAND, 2004, p.141).

\section{Metodologia}

Metodologicamente, para a pesquisa foi importante definir os locais de coleta de água, de forma que apresentasse diferentes tipos de uso e cobertura da terra. Para tanto, elegeu-se pontos de coleta com cobertura de mata ripária, outros usos a exemplo da agricultura. Também foi importante a acessibilidade aos pontos de coleta. A divisão das coletas de água ocorreu no alto curso, médio curso e baixo curso, contemplando os diferentes cursos de água do rio principal. Além de estabelecer a hierarquia fluvial segundo Sthraler (1952). Assim, inicialmente realizou-se a delimitação da bacia hidrográfica, para que com esta informação fossem identificados, os municípios contidos na bacia. Posteriormente, analisou-se e relacionou-se a população urbana e rural entre os anos de 2000 - 2010. A relação entre o aumento e diminuição da população urbana e rural, torna-se importante, de modo que esta dinâmica reflete na utilização dos recursos hídricos e no uso e cobertura da terra. Estes dados foram obtidos através do Atlas do Desenvolvimento Humano no Brasil (2013).

O levantamento topográfico do relevo foi realizado a partir da disponibilidade das imagens de satélite SRTM. Para tanto, foi factível realizar o tratamento da imagem e a partir do geoprocessamento gerou-se o mapa hipsométrico. A hipsometria permite estabelecer as diferenças altimétricas que interferem no poder de carga do canal fluvial, interferindo na quantidade de materiais em suspenção. Estes resultados foram obtidos por meio do processamento das imagens SRTM (Shuttle Radar Topography Mission) adquirida no site da NASA (National Aeronautics and Space Administration). O processamento das imagens foi efetuado no programa QGIS 2.8 (Quantum Gis), pois se trata de um software gratuito que permite o processamento de dados matriciais, vetoriais e cadastrais.

Para gerar o mapa com o NDVI (Índice de Vegetação por Densidade Normatizada), foi necessário a aquisição de imagens do satélite Landsat 7. Desta forma aplicou-se o cálculo do NDVI, utilizando as bandas 3 e 4 de cada imagem, este índice se expressa de -1 a 1 . Para a comparação das bandas foram processadas as imagens de 03/04/2000 e outra de 20/03/2015, a escolha da imagem de satélite se deve à proximidade das datas (dias e meses) entre as duas. Isto foi realizado para não ocorrer discrepância entre os usos, tendo em vista que este usos se diferem no decorrer do ano, principalmente com relação à produção agrícola e pós colheita como solo exposto. Os dados da população foram adquiridos na plataforma Atlas Brasil.

Os diversos tipos de usos e ocupação da terra em relação aos recursos hídricos dos pontos de coleta de água foram visíveis e comprovados por meio das análises de água. Em Campo foram medidos os seguintes parâmetros: Oxigênio dissolvido e temperatura. No laboratório foi medido o PH utilizando o Phmetro.

Em relação aos pontos de coleta de água, o primeiro foi na nascente. Este se situa no curso superior, ou seja, no alto curso, seguidamente a coleta foi no médio curso e por fim no baixo curso. No médio curso, encontra-se a estação de tratamento de água no município de Gaurama que abastece o próprio município e o de Viadutos, portanto, esta estação capta a água do Rio Suzana. No médio e baixo curso as atividades de coleta foram no município de Marcelino Ramos onde encontra-se parte de sua drenagem e, por fim, a foz da bacia hidrográfica. Com a realização do trabalho de campo foi possível realizar a apreciação in loco dos usos que estão presentes neste espaço. Desta forma, sendo de extrema importância entender o contexto em que está se insere. Destaca-se na (imagem 3) os oito pontos onde foram efetuadas as coletas de água para análise laboratorial.

Tratando-se da coleta e análise de água, tanto em campo como no laboratório foram medidos os seguintes parâmetros: o Oxigênio dissolvido que foi medido com o auxílio do Oximetro ainda em campo; o Potencial Hidrogeniônico que foi obtido por meio do Phmetro que teve sua análise em laboratório, e também foi realizado o teste para detectar a quantidade de sólidos em suspenção.

A coleta da água para análise laboratorial foi realizada utilizando garrafas pets, onde previamente inseriu-se água do local de coleta nas garrafas para lavagem objetivando apresentar as mesmas características físico-químicas, posteriormente a total imersão do recipiente no corpo hídrico para que não fosse introduzido juntamente com a água e assim foram refrigeradas em caixa de isopor até chegar ao 
laboratório.

Para a análise da quantidade de sólidos em suspensão realizou-se os seguintes procedimentos:

1 - pré-secagem dos filtros de fibra de vidro por 24 horas em uma estufa com temperatura de $60^{\circ}$.

2 - pesagem dos filtros secos em uma balança de precisão adequada.

3 - filtragem de $300 \mathrm{ml}$ de água

4 - nova secagem de 24 horas em uma estufa com temperatura de $60^{\circ}$.

5 - pesagem final dos filtros.

Após estes procedimentos obteve-se a diferença de peso entre os filtros "sujo-limpo", esta diferença representa os sólidos suspensos na amostra. Para calcular a quantidade de material suspenso nos vários pontos de coleta deste curso hídrico utilizou-se a seguinte fórmula.

A partir da coleta, destes dados foi possível com o auxílio do Excel aplicar a formula e realizar o cálculo entre peso final menos o peso inicial dividido pela

$$
\begin{aligned}
& \mathrm{CSS}=\frac{\mathrm{P} 2-\mathrm{P} 1}{\mathrm{~V}} \cdot 1000 \quad \text { Onde: } \\
& \text { C.S.S. = Concentração de sedimentos em suspensı̃o }(\mathrm{mg} / \mathrm{L}) \\
& \mathrm{P} 1=\text { peso inicial do filtro }(\mathrm{g}) ; \\
& \mathrm{P} 2=\text { peso do filtro com material coletado após secagem em estufa }(\mathrm{g}) ; \\
& \mathrm{V}=\text { volume de água utilizado para filtração }(\mathrm{L}) \\
& 1000=\text { fator conversão para miligramas }
\end{aligned}
$$

Figura 2 - Formula para identificar a quantidade de sólidos em suspensão Fonte: (Nogueira; Cabral; Oliveira, 2012) quantidade de água filtrada e multiplicado por mil, obtendo o resultado elaborou-se os gráficos que serão apresentados nos resultados.

\section{Resultados e Discussões}

\section{Contextualização da área de estudo}

A bacia hidrográfica do Rio Suzana abrange uma área aproximada de $272,1446 \mathrm{Km}^{2}$ de extensão. A altitude da jusante $799 \mathrm{~m}$ e a montante $407 \mathrm{~m}$, sua variação altimetria é de $392 \mathrm{~m}$ (Figura 3). Observando a referida figura, pode-se verificar os diferentes cursos do rio, no alto curso percebe-se a linearidade do fluxo em terreno mais suave, já no médio curso do rio constata-se o início de meandros e no seu entorno vários morros.

Destaca-se a visibilidade da intensidade das curvas de nível nesse setor da bacia. O baixo curso localiza-se próximo da foz e apresenta maior volume de água e menor declividade. Outro ponto a ser destacado foi a realização da classificação da hierarquiza dos cursos de água da bacia, o método utilizado é referente ao elaborado por Arthur Newell Strahller (1912-2002). Esta bacia hidrográfica, que possui como rio principal o Suzana, possui muitas nascentes, evidenciando a presença de cursos de $1^{\circ}, 2^{\circ}, 3^{\circ}$ e $4^{\circ}$ ordem. Desse modo pela classificação de Strahller (1952) seu curso principal é de $4^{0}$ ordem (Figura 4).

A bacia hidrográfica do Rio Suzana está situada no norte gaúcho, esta que tem suas principais nascentes localizadas ainda dentro do Perímetro Urbano do $\mathrm{Mu}$ -

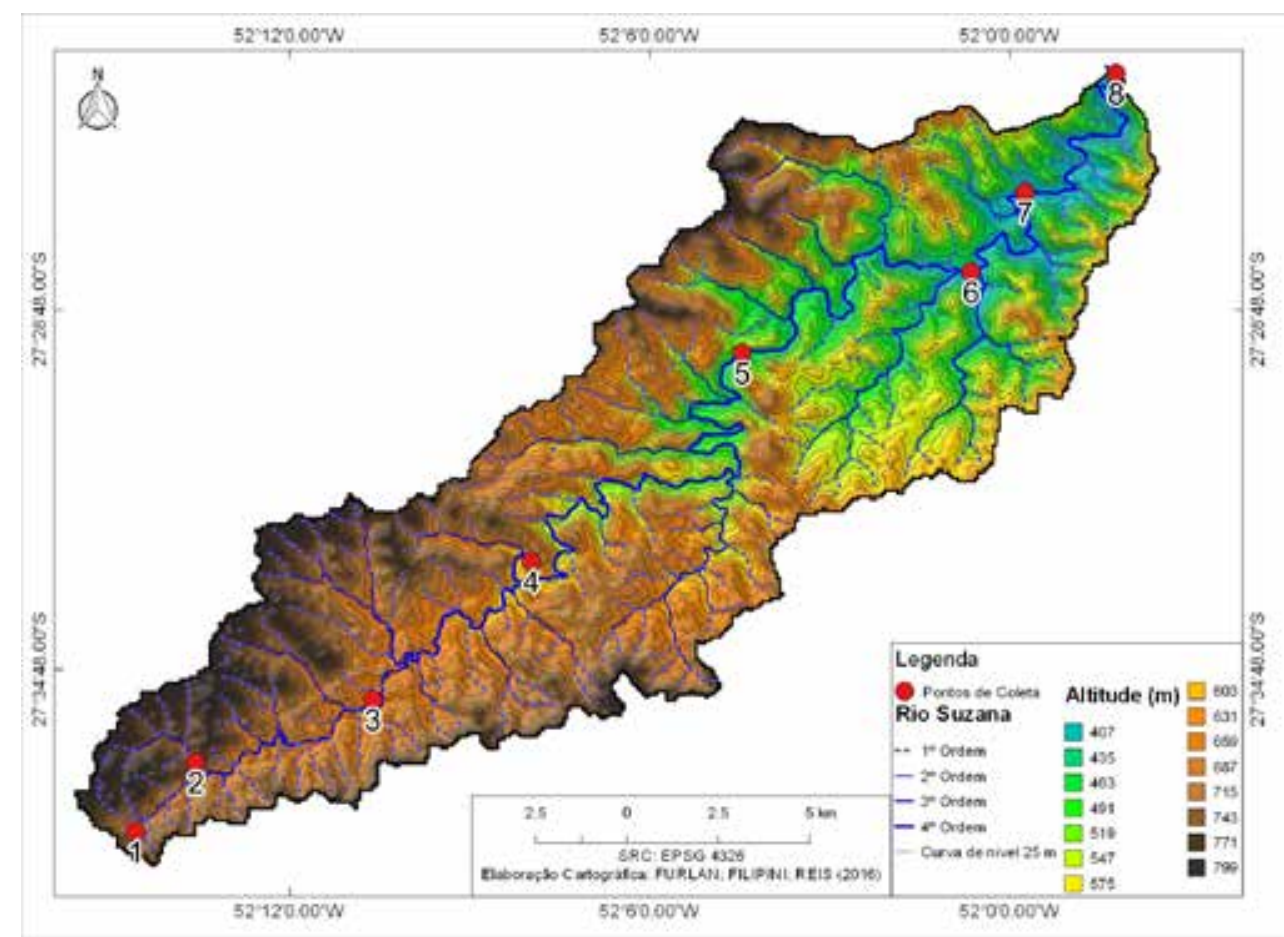

Figura 3 - Mapa hipsométrico da Bacia Hidrográfica do Rio Suzana, RS

Fonte: SRTM (2014) HASENACK; WEBER (2010) 


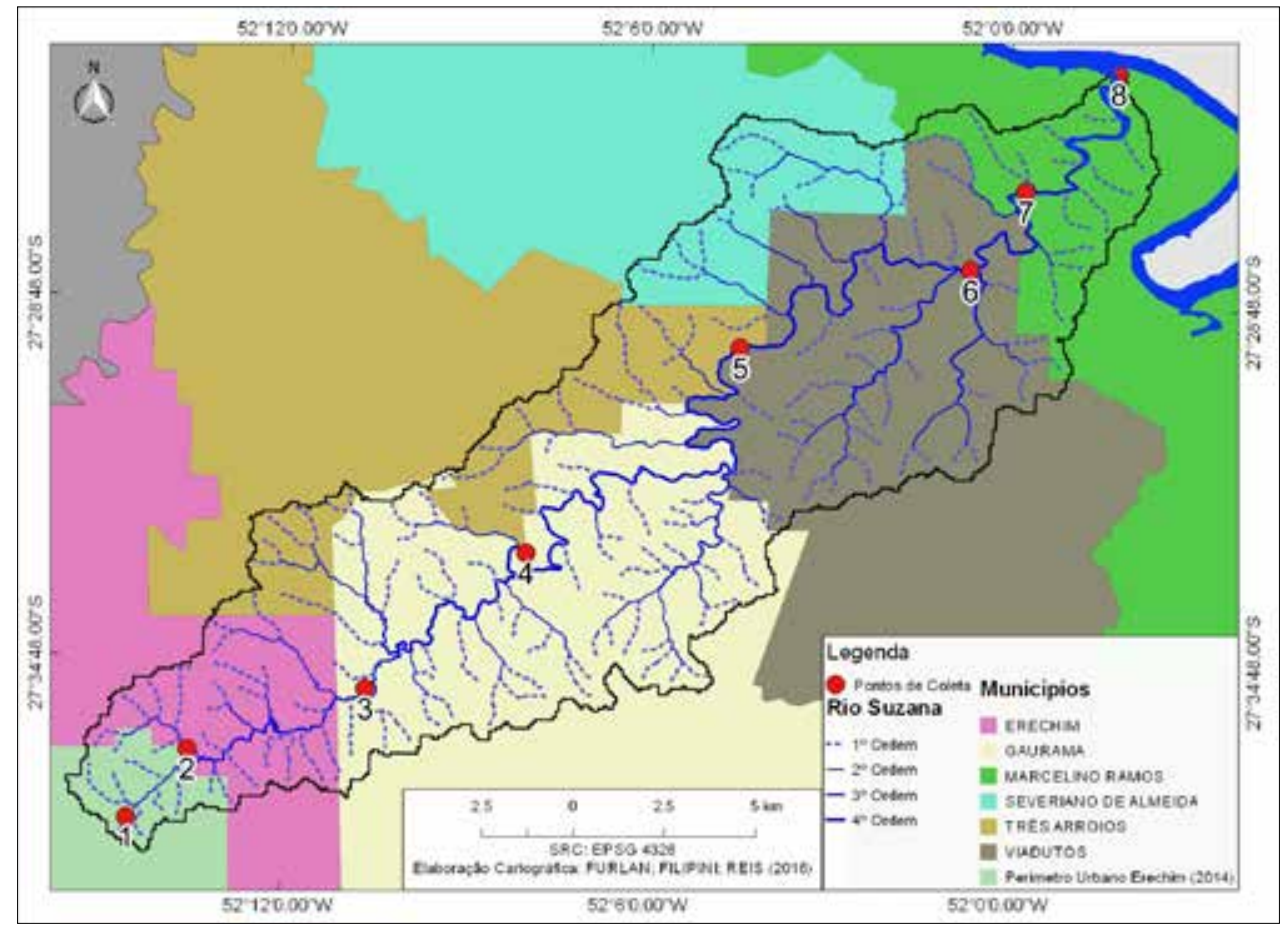

Figura 4 - Limites administrativos Municipais: Bacia Hidrográfica do Rio Suzana, RS Fonte: IBGE (2010); HASENACK; WEBER (2010); PREFEITURA MUNICIPAL DE ERECHIM (2014)

nicípio de Erechim. Além do município de Erechim esta bacia abrange mais cinco munícipios até desaguar no Rio Uruguai. A figura 4, também monstra os limites administrativos, e os pontos de parada para coleta da água.

A bacia hidrográfica do rio Suzana pertence ao comitê de bacia Apuee-Inhandava, mas ao buscar maiores informações sobre a existência de planos de gerenciamento da bacia hidrográfica do Rio Suzana, constatou-se apenas a existência de um plano de manejo da bacia hidrográfica, somente na porção que abrange o município de Erechim. Porém cabe destacar que a bacia hidrográfica deve ser analisada como um todo. Portanto, somente parte da bacia, ou seja, a montante encontrou-se um plano de gerenciamento dos recursos hídricos elaborado em concordância com a prefeitura municipal de Erechim. Por outro lado, o município de Viadutos informou que existe um programa de coleta de resíduos sólidos em todo município.

A partir da visão de planejamento de bacia hidrográfica, vale ressaltar que deve ser gerida por completo, ou de forma integrada, tendo em vista que qualquer alteração em parte da bacia hidrográfica passa a repercutir nas demais partes, pois há troca de energia que ao alterar um elemento natural presente repercute em todo o sistema. Portanto, ao se tratar de bacia hidrográfica deve-se considerar a parte como um todo, ou seja, toda a bacia e as sub-bacias ou bacias de captação para uma escala mais detalhada permitindo que cada parte seja estuda de forma isolada e detalhada assim como de forma integrada todo o conjunto de elementos naturais e antrópicos presentes para obter resultados úteis e significantes, e não de forma segmentada na escala do município. Pois uma Bacia hidrográfica é de responsabilidade do Comitê de Bacia. Uso e ocupação do solo é de responsabilidade dos municípios (ordenamento territorial). Os dois devem estar em sintonia para manter a qualidade e quantidade da água. Destaca-se que o Plano de Manejo da Área de Proteção Ambiental (APA) do Rio Suzana no município de Erechim publicado em 2011, efetuado pela Universidade Integrada do Alto Uruguai e das Missões (URI), Campus de Erechim, mediante convenio com a Prefeitura Municipal através da Secretaria Municipal de Meio Ambiente, é um documento amplo de 234 páginas, mas que apresenta vários pontos questionáveis. Dentre os quais sua abrangência, somente parte da bacia hidrográfica foi estudada não permitindo uma análise integradora, tanto do sistema que envolve a bacia hidrográfica quanto dos municípios que são drenados.

\section{Análise da dinâmica populacional dos muni- cípios contidos na Bacia Hidrográfica}

Ao tratar da influência dos usos e cobertura da terra, é importante destacar a relação que a população estabelece neste sistema. Nas últimas décadas a mecanização da agricultura se consolidou como paradigma dominante no contexto rural, juntamente com este o agronegócio e a monocultura, além da presença da agricultura familiar. Assim, esta temática possui ligação direta com a gestão de bacias hidrográficas e para evidenciar as mudanças procurou-se relacionar o crescimento populacional rural e urbano dos municípios que são drenados pela bacia hidrográfica do Rio 
Suzana. Pois, cabe destacar que a maior área da bacia ocorre sobre o meio rural.

A partir dos dados disponibilizados no Atlas Brasil realizou-se o cálculo da porcentagem da variação da população da década de 2000-2010. No referido período constatou-se o decrescimento da população rural, porém o município de Erechim foi que menos perdeu população rural, seguido do município de Severiano de Almeida, conforme as figura 4 e 5 onde é possível observar esta variação entre o crescimento da população urbana e o decréscimo da população rural.

O município de Marcelino Ramos pode ser considerado como caso isolado, pois teve decrescimento, tanto da população urbana quanto da população rural, isto é explicado devido ao impacto causado pela Usina Hidroelétrica de Itá, que atingiu grande parte da área do município. Em relação da população urbana, verifica-se que os municípios de Três Arroios e Severiano de Almeida foram os que tiveram maior taxa de crescimento da população urbana. Em contrapartida, Viadutos e Gaurama apresentaram diminuição acentuada de população rural, embora não apresentar aumento equivalente na população urbana. Este fato demonstra fortes indícios de migração desta população para outros municípios, evidenciando o esvaziamento do espaço rural e a concentração da população residente no espaço urbano.

\section{Análises do Índice de Vegetação por Densida- de Normatizada (NDVI)}

Ao tratar da cobertura e preservação na bacia hidrográfica foi realizado o NDVI, para estabelecer uma posterior relação com os parâmetros da qualidade da água e diferentes comparar a preservação da floresta nos diferentes trechos da bacia hidrográfica. Percebe-se claramente a diminuição da vegetação no curso alto e médio entre os anos de 2000 e 2015 (Figuras 6 e 7).

$\mathrm{Na}$ visita in loco comprovou-se a grande presença de monoculturas extensivas e de plantas exóticas, a citar eucaliptos e pinus. Assim, constatou-se que os locais mais afetados pelo desmatamento foram o alto e parte do médio curso, também se verificou uma diminuição acentuada nas nascentes principalmente, nos afluentes a esquerda da bacia hidrográfica. Esta diminuição drástica ocorreu em quinze anos, evidenciando que os órgãos competentes deverão intervir e barrar a derrubada da floresta. Desse modo, foi possível identificar "in situ" a presença de eucalipto e pinus. Porém, os locais com declividade suave mais plana considerada apropriada

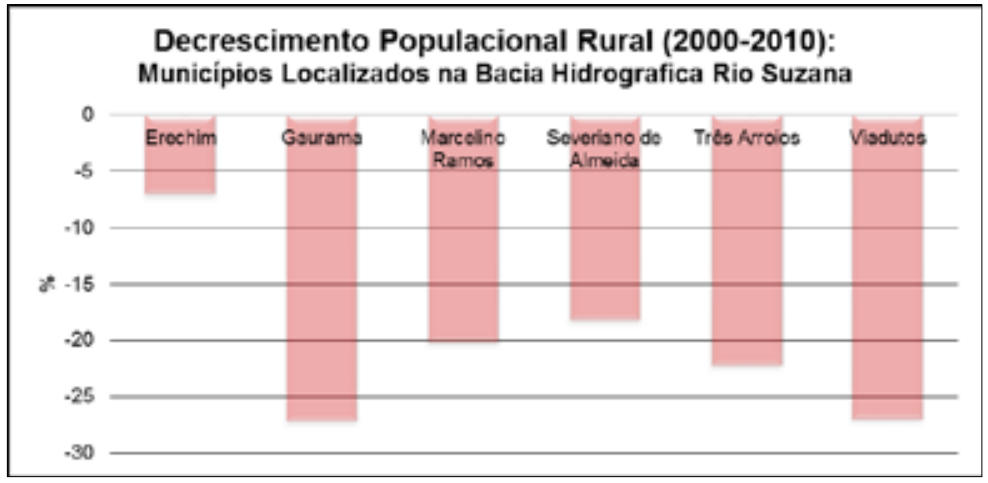

Figura 4 - Decréscimo população rural (2000-2010)

Fonte: Atlas Brasil (2013)

Org.: Os autores.

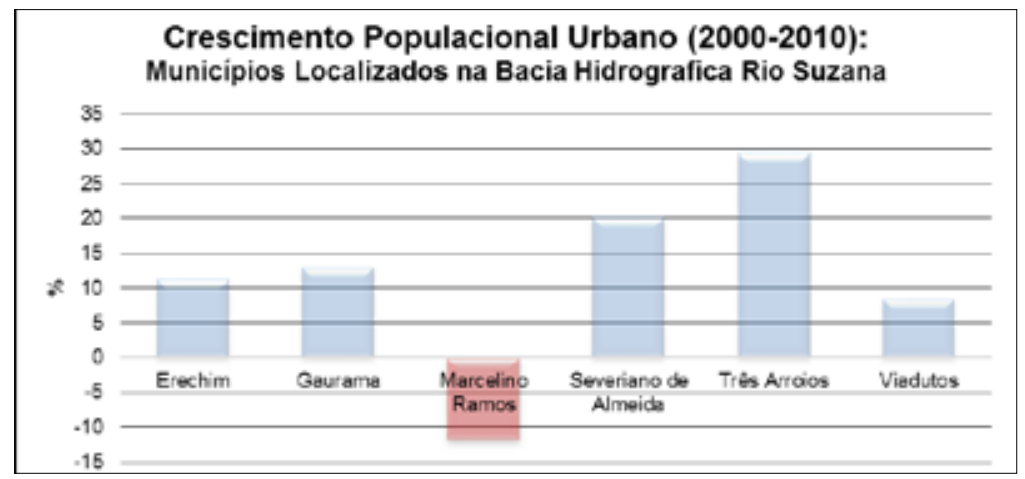

Figura 5 - Crescimento populacional urbano (2000-2010)

Fonte: Atlas Brasil (2013)

Org.: Os autores. 


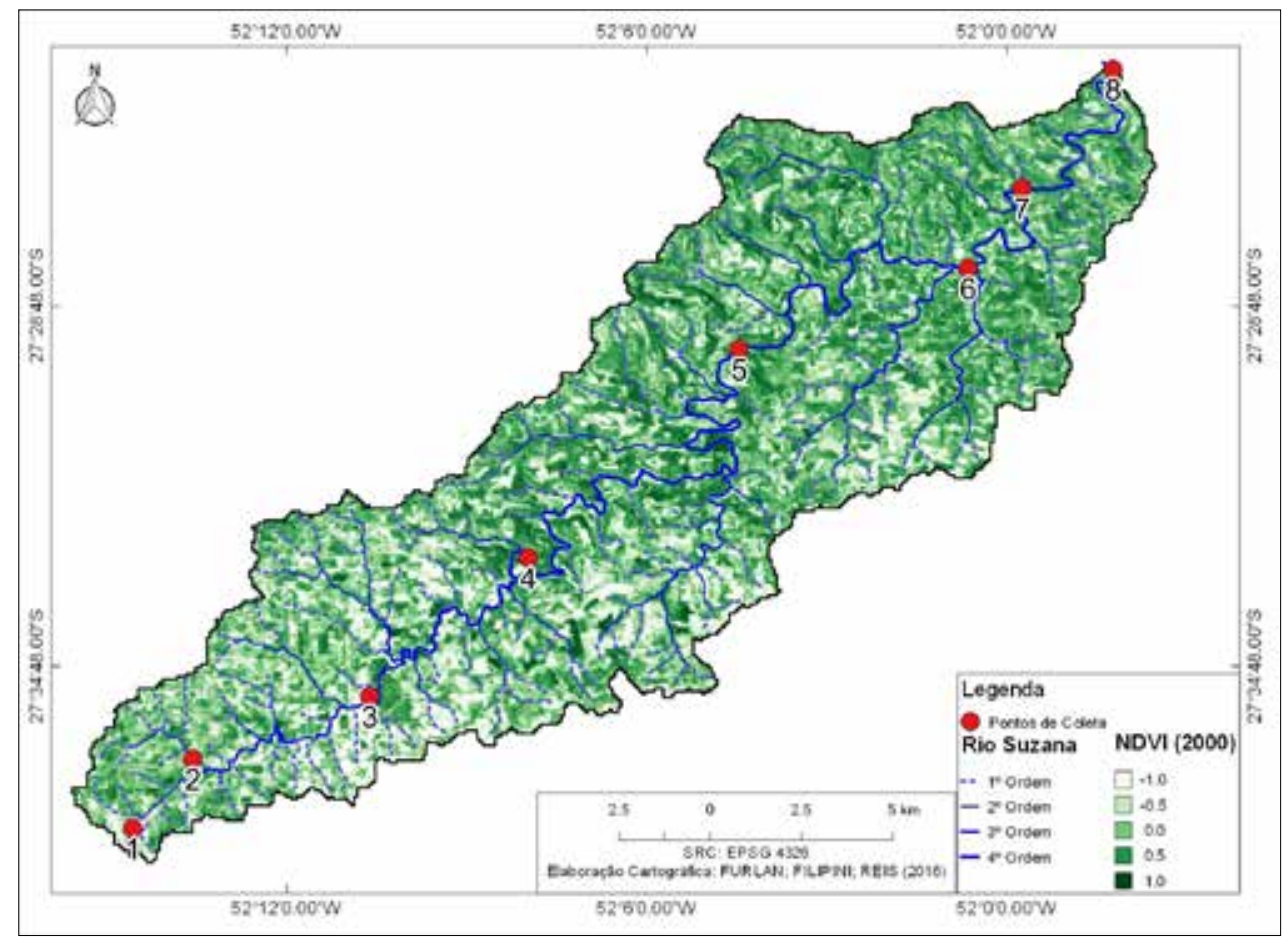

Figura 6 - Índice de Vegetação por Densidade Normatizada (NDVI) Fonte: Landsat 7 (2000)

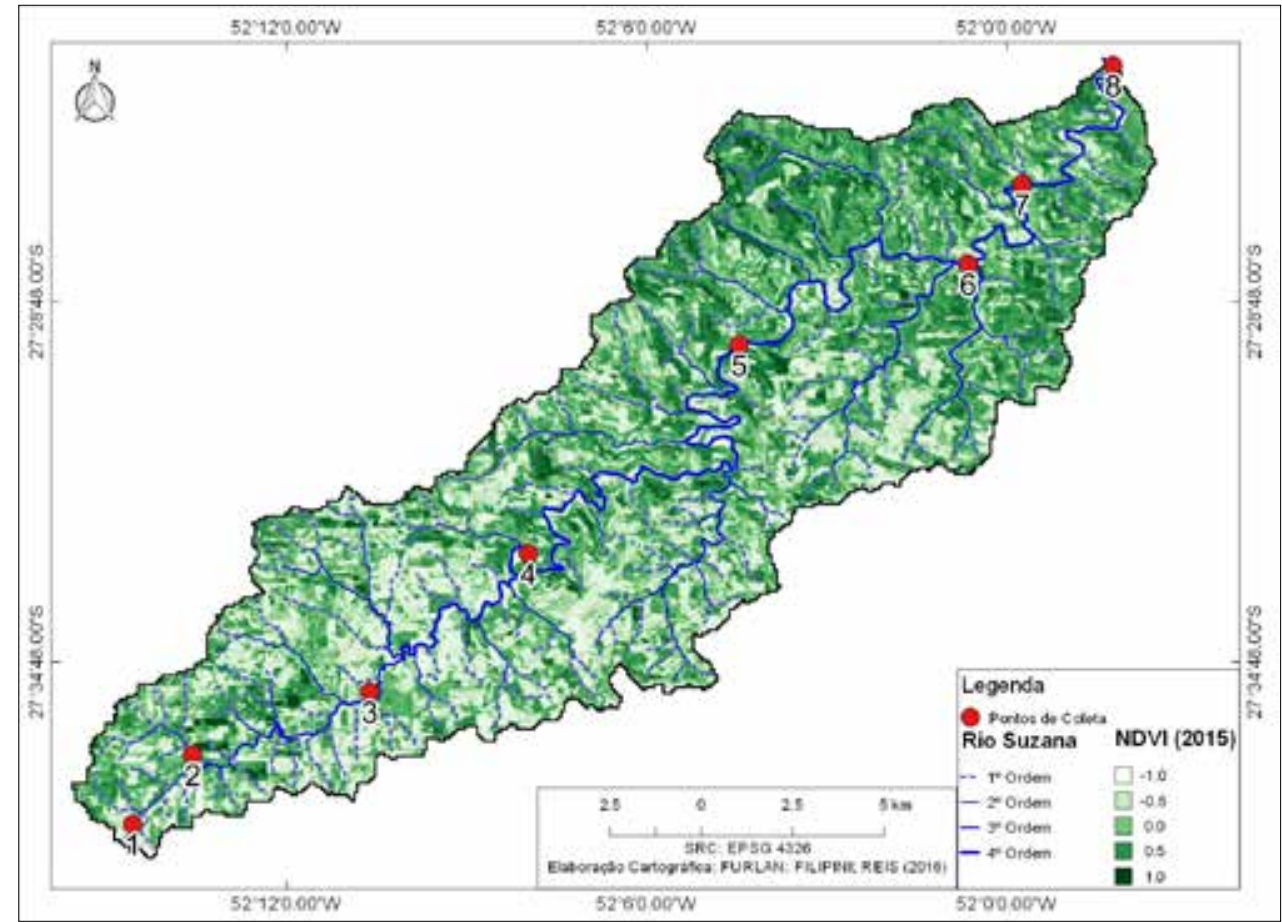

Figura 7 - Índice de Vegetação por Densidade Normatizada (NDVI)

Fonte: Landsat 7 (2015)

para uso de maquinas agrícola são transformados em lavouras de monocultura, já os locais que não apresentam topografia apropriada para o plantio de grãos tornou-se área de plantio de eucalipto e pinus. Vale ainda ressaltar que a diminuição da população no meio rural, possivelmente foi ocasionada pela mecanização da agricultura e monocultura instalada a partir da década de 70, principalmente com o advento da soja.

\section{Registros e análise dos pontos de coleta}

A partir dos pontos de coleta foi possível realizar análise da paisagem local e também alguns parâmetros de água foi possível estabelecer a relação e discussão dos 
elementos que compõe a paisagem aliada aos diferentes tipos de usos e cobertura da terra presentes nas proximidades. Assim, a relação entre o meio físico, biótico e antrópico são de extrema importância para estabelecer uma avaliação e planejamento ambiental integrada.

A partir da experiência empírica e registros fotográficos relacionadas as dinâmicas de cada porção da Bacia Hidrográfica do Rio Suzana realizou-se uma descrição local. No primeiro ponto, a montante da bacia hidrográfica, mais precisamente na nascente, situada no perímetro urbano constatou-se o curso natural represado formando dois lagos (Figura 8a), e na sua proximidade uma residência. Em uma propriedade privada com criação de animais domésticos, lazer, onde deveria ser Área de Preservação Permanente (APP), segundo o Código Florestal (LEI 12.651 25/05/2012) dever-se-ia destinar um raio de $50 \mathrm{~m}$ para a proteção das nascentes, porém isso não se aplica na realidade.

O referido local que é uma área particular deveria ser público de uso restrito. A pouca presença de vegetação, arbóreas exóticas e não nativa denotam o uso da terra de forma inadequada, o que foi comprovado pela análise onde a água estava contaminada. Pode-se observar os diversos usos da terra, uma rodovia, uma indústria, habitações e nas proximidades da nascente cobertura de vegetação mista (espécies nativas e exóticas). Para intensificar a ação antrópica encontra-se um depósito de detritos resultantes da obra na rodovia e canalização do esgoto pluvial. Estas ações causam impactos diversos que influenciam na qualidade da água, tendo em vista que o aterro causa assoreamento das margens do leito do rio, bem como o esgoto causa impactos negativos sobre a bacia hidrográfica.

O ponto de coleta 2 encontra-se no limite do perímetro urbano de Erechim. Este local é uma zona de transição de diferentes usos da terra, vale ressaltar que "nas bordas da cidade, é comum existir uma "faixa de transição" entre o uso da terra tipicamente rural e o urbano. Essa faixa de transição é chamada, entre os geógrafos anglo-saxões, de franja rural-urbana, e, entre os franceses, comumen- te, de espaço periurbano" (SOUZA, 2011, p.27). Neste observou-se lavouras de soja em fase inicial de plantio, nas proximidades do curso de água com alguns remanescentes da mata ciliar. Na figura $8 \mathrm{~b}$ um dos usos do local, que consiste as chácaras de lazer junto ao curso de água, com barramento no intuito de represar o rio para usos particulares. Mas, segundo a Legislação vigente, neste local, dever-se-ia ter uma vegetação ciliar que pode variar de 5 a 30 metros conforme o tamanho do curso e da propriedade. Também identificou-se desvio da água do curso original, ao longo do percurso realizado.

O ponto de coleta e análise 3 encontra-se na zona rural. Neste o curso hídrico já apresenta maior vazão, e percebe-se a presença de vegetação ciliar, porém abaixo do ideal. A figura 9a demonstra o uso agrícola onde podem ocorrer alterações que reflete diretamente no balanço hídrico, sobre esta perspectiva Coelho-Neto e Avelar (2007, p.67), enfatizam que estas mudanças induz a diminuição de "[...] estoques de águas guardadas neste meio subterrâneo. Por outro lado, os solos expostos se tornam os mais vulneráveis à erosão superficial por sua exposição direta às chuvas e aumento do escoamento superficial nas encostas e fundos de vales. Esta carga de sedimentos muitas vezes é acompanhada por uma carga solúvel tóxica, especialmente nas áreas sob uso agrícola [...]" (COELHO-NETO; AVELAR, 2007, p.67).

A silvicultura pode ocasionar vários prejuízos tanto para o solo quanto para os cursos hídricos. Pois a cultura do eucalipto pode causar a queda da produtividade biológica e influenciar diretamente no ecossistema de três maneiras de acordo Coelho-Neto e Avelar (2007, p.73):

a) a alta demanda de água dos eucaliptos esgota a umidade do solo e acaba com a recarga da água subterrânea; b) a pesada demanda por nutrientes cria um déficit anual que desestabiliza o ciclo de nutrientes; c) a liberação de substâncias química alopática afeta o crescimento de plantas e de micro-organismos do solo, reduzindo, assim, ainda mais a fertilidade dos solos.

O ponto 4 situa-se junto a Barragem de captação que abastece as cidades de Gaurama e Viadutos, que

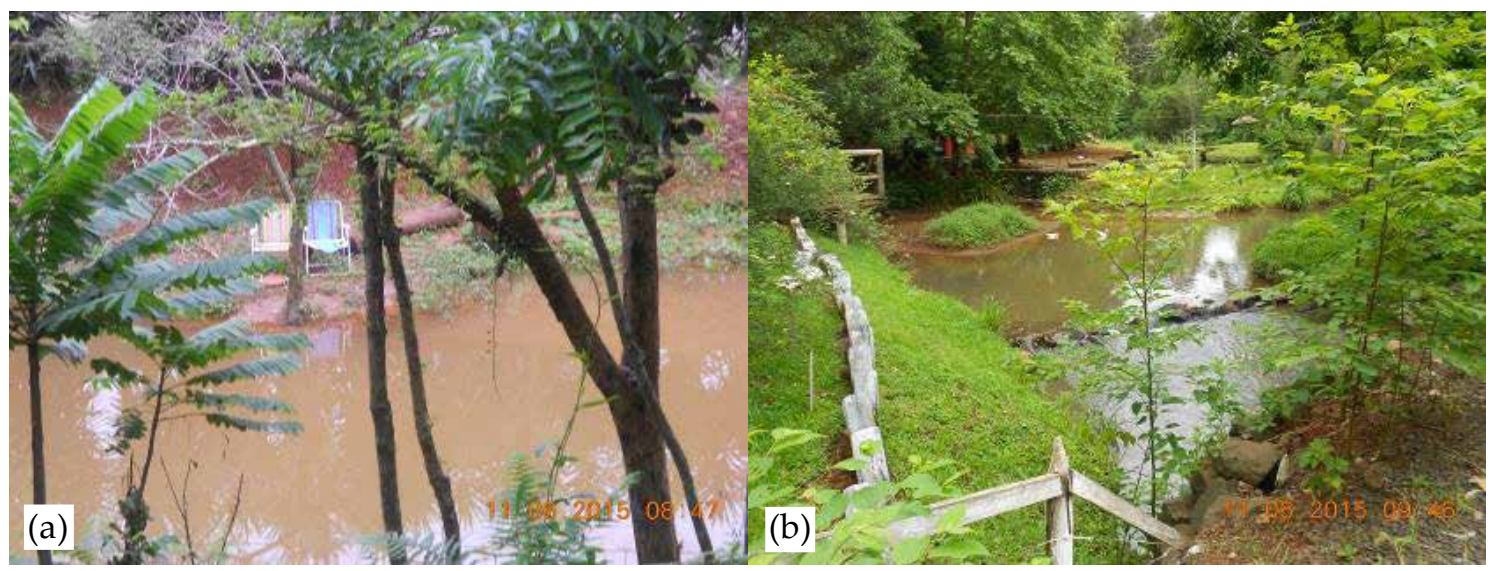

Figura 8ab - Ponto de coleta 1 e 2

Fonte: Autores 


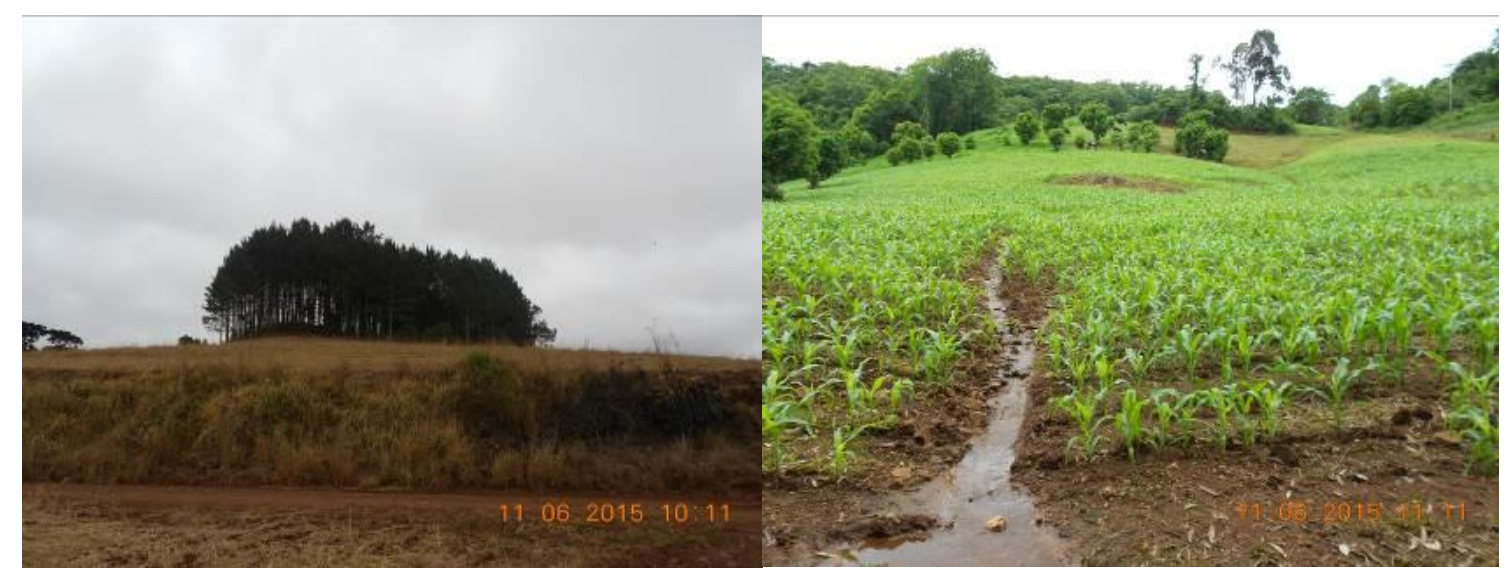

Figura 9 a b - Ponto de coleta 3 e 4

Fonte: Autores

pode ser identificado na figura $9 \mathrm{~b}$ uma nascente. Está localizada no meio a uma área de pastagem de gado leiteiro e na sequência percorre uma lavoura de milho até encontrar o curso principal. Considerado em situação irregular conforme a legislação vigente. No ponto 5 foi possível identificar maior vazão perante os outros pontos observados. Este localiza-se no curso médio junto ao leito principal da bacia hidrográfica. Ao realizar uma comparação com o ponto 4 , cabe ressaltar que está localizado a montante da barragem da Corsan citada anteriormente. Trata-se do curso médio, forte presença de vegetação nas margens do rio em relação aos demais pontos. Constatou-se durante o trajeto que o entorno deste local possui topografia acentuada, por conseguinte as lavouras não são intensas e nem extensas predominando então pequenas lavouras de cereais e monocultivo de erva-mate. Porém, favorece que sejam desenvolvidas atividades que não necessitem de áreas extensas, mas que são grandes geradoras de poluentes, ressaltasse a suinocultura e a avicultura que são desenvolvidas em sistema de integração.

O ponto 6 encontra-se na zona rural, cujo o uso do solo restringe-se a agriculta e silvicultura. Na figura 10 a em um primeiro momento demonstra mata ciliar, porém, se observar detalhadamente a paisagem, percebe-se a simetria de uma plantação de eucaliptos, onde deveria constar mata nativa ciliar. A plantação denota a topografia do local, em ambas as margens do corpo hídrico, tendo em um lado plantação de erva mate e demais vestígios do cultivo de outras culturas, assim como a presença de silvicultura.

O ponto de coleta 7, junto ao baixo curso do Rio Suzana, observa-se diferentes tipos de usos, inclusive agricultura próximo as margens do rio. Neste local, também foi perceptível que o curso hídrico apresenta uma vazão maior que nos demais e tratando-se de vegetação apresenta insuficiência e pouca quantidade de mata ciliar. Na Figura 11a, observa-se fragmentos de um antigo barramento onde se utilizava água do rio como forma motriz de um moinho, é um local relativamente preservado, porém caracteriza-se tanto a fins de lazer como para produção rural. Segundo relato do proprietário, este local recebe visita de escola com fins de educação ambiental. Vale salientar que este ponto é

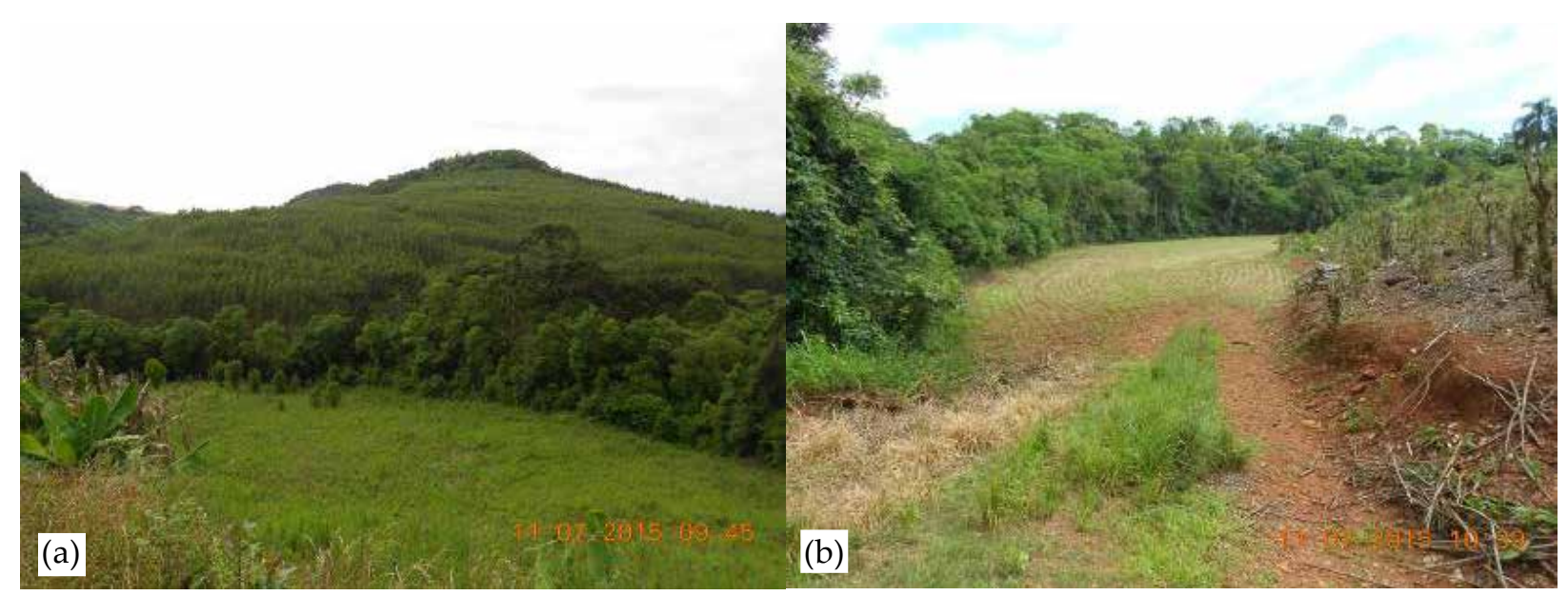

Figura $10 \mathrm{a}$ b - Ponto de coleta 5 e 6

Fonte: Autores 


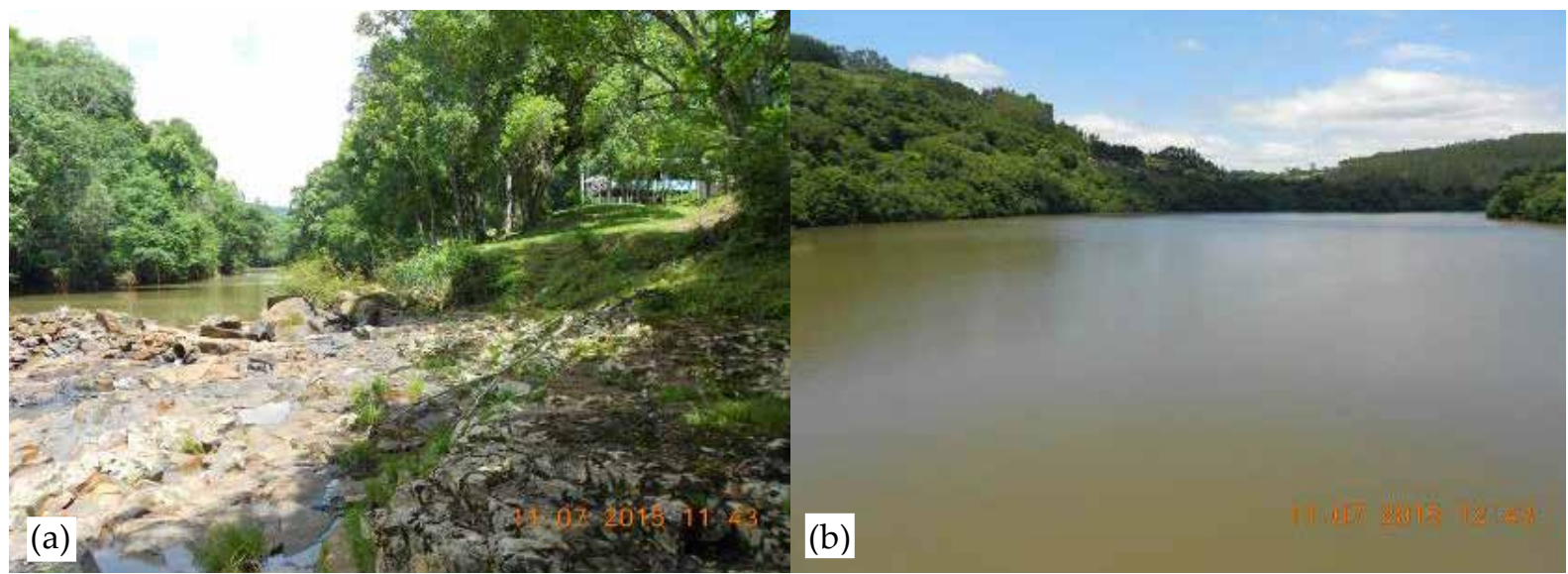

Figura $11 \mathrm{a}$ b - Ponto de coleta 8

Fonte: Autores

próximo da cota máxima de inundação do lago da Usina Hidroelétrica de Itá. Assim, na figura 11a, observa-se a presença da lamina d'agua barrada, e a direita da figura, a presença de uma moradia. Vale ressaltar que este corpo hídrico sofre influência do barramento, sendo praticamente um lago, no local foi possível observar vegetação ciliar rala em suas margens.

O último ponto de coleta encontra-se na foz do Rio Suzana, onde o mesmo desagua no Rio Uruguai. Hoje este local sofre influência da UHE de Itá, como pode-se observar na figura $11 \mathrm{~b}$ tamanha proporção que este curso tomou com o barramento do Rio Uruguai. Os usos da terra ao entorno deste ponto fica restrito principalmente, a silvicultura e criação de gado, tendo em vista que a topografia do terreno que não permite a mecanização intensiva para o desenvolvimento da agricultura.

\section{Análise da água}

A análise da água foi realizada a partir das amostras coletadas durante trabalho de campo, e seus resultados foram obtidos em campo e no laboratório. Destaca-se que foram analisados os seguintes parâmetros: $\mathrm{Ph}$, sólidos em suspensão e oxigênio dissolvido, para esses parâmetros a Resolução 357 de 17 de março de 2005 do Conselho Nacional do Meio Ambiente (CONAMA) traz valores de referência, que são considerados ideais. Para o potencial hidrogeniônico (Ph) o qual indica a acidez, neutralidade ou alcalinidade de uma solução aquosa, em uma escala que vai de 0 a 14, tendo os parâmetros menores que sete sendo ácidos iguais a sete neutros e maiores de sete básicos. No trabalho de campo foram coletadas 8 amostras ao longo da bacia, e o resultado, desse parâmetro, pode ser observado na figura 16.

De acordo com a figura 12, constata-se que nos pontos 1 e 2 o Ph é baixo (ácido), muito provavelmente pelo fato de estarem localizados no perímetro urbano e possuírem maior concentração de agentes químicos e biológicos dissolvidos. O ponto 3 a 7, pelo fato do rio aumentar seu volume, ocorre à depuração da água, nesses pontos apresentam-se valores muito próximos da neutralidade. No ponto 8 há um aumento na acidez, neste ponto a água apresenta fluxo muito lento, por se tratar de um lago de uma UHE. Vale enfatizar que com o represamento do Rio Uruguai, rio onde o Suzana desagua, ocorre uma mistura dessas águas, o que pode acarretar mudanças nesse índice. Vale ressaltar que o $\mathrm{pH}$ isoladamente não pode indicar a qualidade da água, mas ele pode ser um indicio de que há algum contaminante presente no corpo hídrico que esteja afetando esse índice.

Na figura 13, encontra-se a quantidade de sólidos em suspensão contidos na água, onde os materiais em suspensão podem indicar a presença de elementos contaminantes, mas para sabermos quais são os sólidos em suspensão seria necessária uma análise química concomitante. Esses índices variam diretamente com o poder de arrasto do rio, que por sua vez é influenciado pela relação entre volume de água, declividade do leito, e interferências físicas do leito (barragens).

Outro parâmetro analisado foi o oxigênio dissolvido. Esta análise foi realizada ainda em campo por meio do Oxímetro. A concentração ideal desse elemento, Segundo a Resolução 357 de 17 de março de 2005, do CONAMA, é igual ou superior a $5 \mathrm{mg} / \mathrm{L}$. Nas medições realizadas a campo dos oito pontos apenas o ponto 1 apresentou um valor abaixo do ideal, como podemos ver na figura 14. Esse fato pode estar relacionado ao ponto de represamento, estagnando a água diminuindo o oxigênio presente na água.

Desse modo, cabe destacar que para uma análise mais concisa da qualidade da água se faz necessário a averiguação de outros elementos presentes na água, tais como: metais pesados, coliformes fecais, agrotóxicos, sólidos dissolvidos. Mesmo assim, a partir dos parâmetros analisados é possível obter indicativos sobre a qualidade da água. 


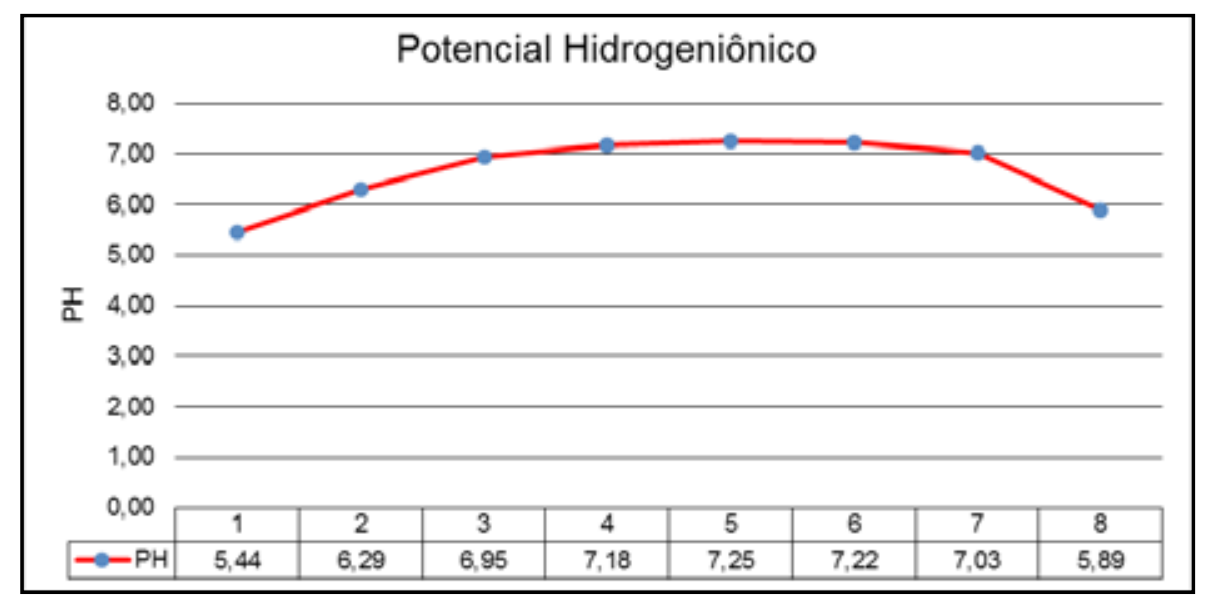

Figura 12 - Gráfico Potencial Hidrogeniônico Fonte: Autores

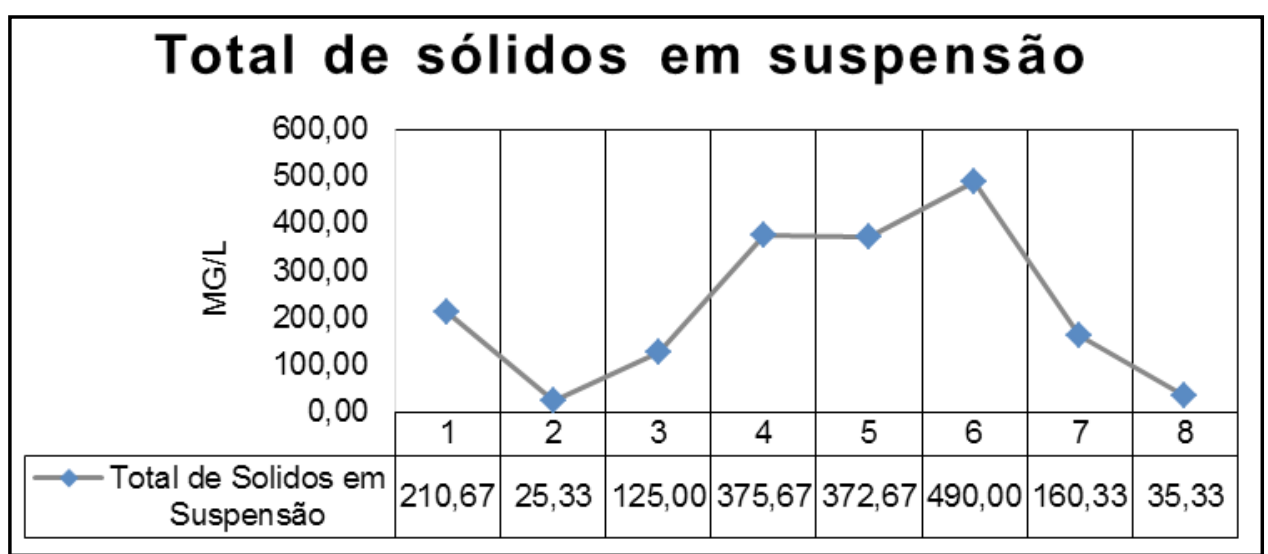

Figura 13 - Gráfico total de sólidos em suspensão Fonte: Autores

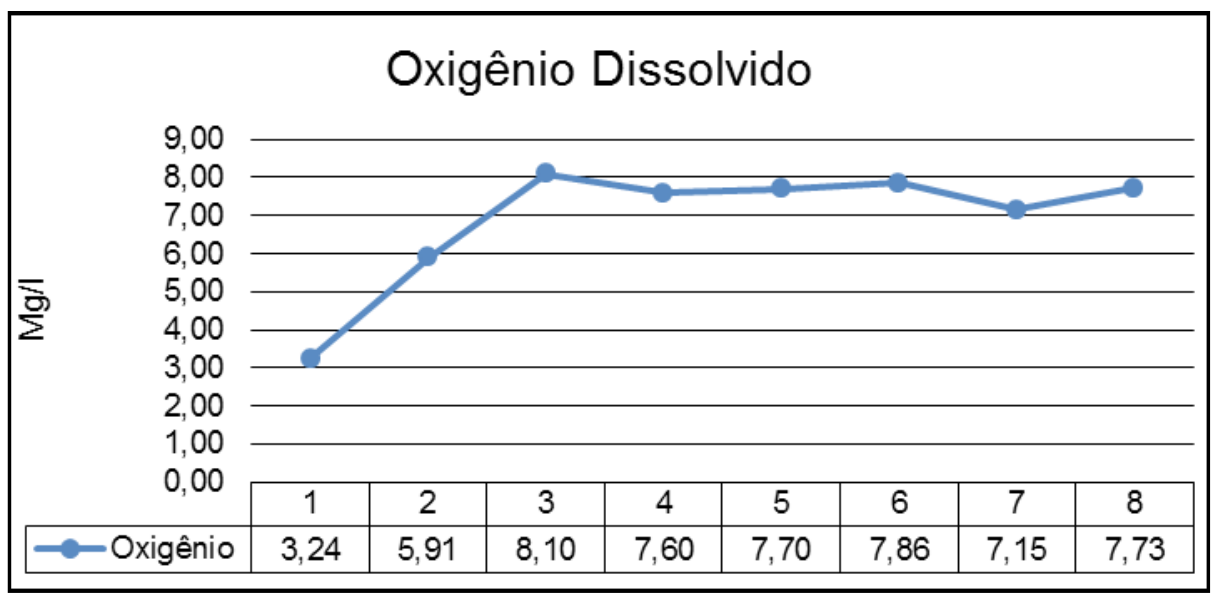

Figura 14 - Gráfico Oxigênio dissolvido Fonte: Autores

\section{Considerações finais}

O uso e a cobertura da terra em uma bacia hidrográfica são de extrema importância por influenciar diretamente sobre os parâmetros da qualidade da água. Com o gerenciamento correto do ambiente terrestre reflete positivamente sobre o ecossistema aquático. Para contemplar este quesito, a preservação da mata ciliar é um elemento primordial. Porém, na bacia hidrográfica do Rio Suzana encontra-se um déficit quanto a preservação da mata ciliar, e observou-se diferentes tipos de usos e cobertura da terra configurando conflito em vários pontos de coleta de água. Portanto, dois elementos foram considerados importantes neste estudo: a existência da vegetação, os outros tipos de usos do solo 
e a população (ser humano) como agente transformador.

Recomenda-se uma análise integrada em toda a bacia hidrográfica, pois é necessário analisar múltiplos elementos para obter uma análise concisa da realidade. No caso da bacia em voga ocorreu uma diminuição da população rural e concomitantemente ocorreu um aumento de áreas de lavouras, principalmente monoculturas. Apenas nas áreas mais íngremes que a mata esta com maiores índices de vegetação, salvo os locais que por não serem mecanizáveis encontram-se plantações de eucaliptos e pinus. Desta forma tem-se o decréscimo da população rural que ocasionou aumento da população urbana em algumas cidades, visto que este elemento também influencia a bacia hidrográfica, pois o município de Viadutos e Gaurama são abastecidos por este rio. Com o aumento da população também ocorre demanda para se obter água encanada. Com o aumento da população urbana ocorre aumento da emissão de esgoto doméstico, aliado a isto, é pertinente ter uma gestão de bacia responsável que aponte todos estes elementos que possuem influência direta ou indireta na qualidade da água e realizar mudanças que visam à melhoria ambiental.

A vegetação sofreu uma diminuição expressiva, pois a vegetação densa foi substituída por lavouras rentáveis de monoculturas. Considera-se a importância a observação empírica, que vem auxiliar nas análises realizadas em laboratório, comprovando a necessidade e a importância do trabalho de campo para o geógrafo. Com o presente trabalho foi possível elencar e concatenar vários elementos, onde um deles é a análise da paisagem, pois esta é uma importante unidade para abordar a relação entre sociedade e natureza. Por fim a análise da água possibilitou um contato com instrumentos e metodologias laboratoriais, embora as análises realizadas não forem suficientes para indicar a qualidade da água. Mas, a visão empírica possibilitou uma relação e uma análise crítica dos usos da terra que repercutem na água e passam a modificar as características físicas, químicas e biológicas da água.

\section{Referências}

ATLAS DO DESENVOLVIMENTO HUMANO NO BRASIL. Disponível em: < http://www.atlasbrasil.org. br/2013/ > Acesso em: 25 nov. 2014.

BERTRAND. G. Paisagem e geografia física global: esboço metodológico. Tradução Olga Cruz. Revista RA'E GA, Curitiba, n. 8, p. 141-152, 2004.

BRASIL. Código Florestal (LEI no 12.651). Brasília: 2012. Disponível em: <http://www.planalto.gov.br/ccivil_03/_ ato2011-2014/2012/lei/112651.htm> Acesso em: 25 nov. 2014.

BRASIL. Código Civil. Lei 9433 de 8 de janeiro de 1997. Sistema Nacional de Gerenciamento de Recursos Hídricos. Brasília, 1997. Disponível em: <http://www.planalto.gov.
br/ccivil_03/leis/L9433.htm> Acesso em: 06 jun. 2016.

COELHO-NETTO, A. L; AVELAR, A. de S. O uso da terra e a dinâmica hidrológica: comportamento hidrológico e erosivo de bacias de drenagem. In: SANTOS, R. F. dos (Org). Vulnerabilidade Ambiental: desastres naturais ou fenômenos induzidos? Brasília: Ministério do Meio Ambiente, 2007.

CONSELHO NACIONAL DO MEIO AMBIENTECONAMA. Resolução no 357, de 17 de março de 2005 Disponíveis em: <http://www.mma.gov.br/port/conama/ res/res05/res35705.pdf> Acesso em: 06 jun. 2016.

ERECHIM. Plano de manejo da área de proteção ambiental do Rio Suzana. Disponível em: <http://www.pmerechim. rs.gov.br/uploads/files/Plano_Manejo_APA_Rio_Suzana_ Dez_2011.pdf> Acesso em: 25 nov. 2014

HASENACK, H.; WEBER, E.(org.) Base cartográfica vetorial contínua do Rio Grande do Sul - escala 1:50.000. Porto Alegre: UFRGS Centro de Ecologia. 2010. 1 DVDROM. (Série Geoprocessamento n.3). ISBN 978-85-6348300-5 (livreto) e ISBN 978-85-63843-01-2 (DVD). Disponível em: <http://www.ecologia.ufrgs.br/labgeo/arquivos/ download Acesso em: 25 nov. 2014.

NOGUEIRA, P. F; CABRAL, J. B. P; Oliveira, S. F. Analise da concentração dos sólidos em suspensão, turbidez e TDS nos principais afluentes do reservatório da UHE barra dos Coqueiros-GO. REVISTA GEONORTE, v.3, n.4, p. 485-494, 2012

NOVO, E. M. L. de M. Sensoriamento Remoto: Princípios e Aplicações. 2 ed. São Paulo: Edgar Blucher, 1995.

LIMA, V. A Sociedade e a Natureza na paisagem urbana: análise de indicadores para avaliar a qualidade ambiental. 2013, 358f. Tese (Doutorado em Geografia) Universidade Estadual Paulista, Faculdade de Ciências e Tecnologia, Presidente Prudente, 2013.

SANTOS, R F dos. Planejamento ambiental - teoria e pratica. São Paulo: Oficinas de textos, 2004.

SOUZA, M. L de. ABC do Desenvolvimento Urbano. 6 ed. Rio de Janeiro: Bertrand Brasil, 2011.

SHUTTLE RADAR TOPOGRAPHY MISSION (SRTM) Disponível em: <http://earthexplorer.usgs.gov/> Acesso em: 06 jun. 2015.

SILVA, G. J. F da; ALMEIDA, N. V. Degradação ambiental no município de Parari-PB: uma análise por meio de sensoriamento remoto. Revista Geografar - Curitiba, v.10, n.2, p.140-164, dez./2015 